\title{
"If It Tastes Good, I'm Drinking It": Qualitative Study of Beverage Consumption Among College Students
}

\section{Citation}

Block, Jason P., Matthew W. Gillman, Stephanie K. Linakis, and Roberta E. Goldman. 2013. "'If It Tastes Good, I'm Drinking It': Qualitative Study of Beverage Consumption Among College Students." Journal of Adolescent Health 52 (6) (June): 702-706. doi:10.1016/ j.jadohealth.2012.11.017.

\section{Published Version}

doi:10.1016/j.jadohealth.2012.11.017

\section{Permanent link}

http://nrs.harvard.edu/urn-3:HUL.InstRepos:32295308

\section{Terms of Use}

This article was downloaded from Harvard University's DASH repository, and is made available under the terms and conditions applicable to Other Posted Material, as set forth at http:// nrs.harvard.edu/urn-3:HUL.InstRepos:dash.current.terms-of-use\#LAA

\section{Share Your Story}

The Harvard community has made this article openly available.

Please share how this access benefits you. Submit a story.

Accessibility 


\title{
"If it Tastes Good, I'm Drinking It": Qualitative Study of Beverage Consumption among College Students
}

\author{
Jason P. Block, MD, MPH ${ }^{1}$, Matthew W. Gillman, MD, SM${ }^{1}$, Stephanie K. Linakis, $\mathbf{M S}^{1}$, and \\ Roberta E. Goldman, PhD ${ }^{2,3}$ \\ ${ }^{1}$ Department of Population Medicine, Harvard Medical School/Harvard Pilgrim Health Care \\ Institute, Boston, MA \\ ${ }^{2}$ Department of Family Medicine, Alpert Medical School of Brown University, Providence, RI \\ ${ }^{3}$ Department of Society, Human Development, and Health, Harvard School of Public Health, \\ Boston, MA
}

\begin{abstract}
Purpose-This study examined how college students choose beverages and whether behavioral interventions might reduce their heavy consumption of sugar-sweetened beverages.

Methods-From April to June 2010, 90 students participated in 12 focus groups at 6 colleges in Massachusetts and Louisiana. The study team undertook a group content analysis of the verbatim focus group transcripts using the immersion-crystallization method.

Results-The mean age of participants was 19 years. 50\% were white, and $47 \%$ were black. Several themes emerged in focus groups: taste is paramount; price is important but secondary; health and nutritional content of beverages are of limited interest; juice has a "health halo"; and water is consumed primarily for hydration. Students were often highly fixated on favorite sugarsweetened beverages. Price was uniquely important for good-tasting beverages costing less than one dollar. Some students reported calorie content as important for food choices, but most had no awareness of beverage calorie content. Students' negative perceptions of sugar-sweetened beverages focused largely on the "dangers" of sugar and chemicals in sodas. They expressed particular concern about soda's corrosive chemical properties or diet soda causing cancer. The health halo for juice persisted even with some recognition of high sugar content. Students thought shocking educational messages would be necessary to get them to reduce consumption of sugarsweetened beverages.
\end{abstract}

Conclusions-Among college students, taste and price were the most important factors in choosing beverages. Interventions using shocking visual images or providing low-cost or free water may conquer taste and brand preference to reduce sugar-sweetened beverage intake.

(C) 2012 Society for Adolescent Medicine. Published by Elsevier Inc. All rights reserved.

Corresponding Author: Jason P. Block, MD, MPH, Obesity Prevention Program, Department of Population Medicine, Harvard Medical School/Harvard Pilgrim Health Care Institute, 133 Brookline Avenue, $6^{\text {th }}$ Floor, Boston, MA 02215, 617-509-9841 (phone), 617-509-9853 (fax), Jason_block@ harvardpilgrim.org.

Dr. Block presented results of this study, in part, at the Annual Meeting of the Society of General Internal Medicine in May 2011 and the Annual Meeting of The Obesity Society in October 2011.

Conflicts of Interest: None declared

Publisher's Disclaimer: This is a PDF file of an unedited manuscript that has been accepted for publication. As a service to our customers we are providing this early version of the manuscript. The manuscript will undergo copyediting, typesetting, and review of the resulting proof before it is published in its final citable form. Please note that during the production process errors may be discovered which could affect the content, and all legal disclaimers that apply to the journal pertain. 


\section{Keywords}

obesity; nutrition; soft drinks; adolescence; young adults; qualitative research

\section{Introduction}

Weight gain early in life is common and portends life-long obesity for many Americans (14). The transition to college appears to be an especially challenging period (5-9). Blunting the "freshman 15" and any additional weight gain during the college years could be an important tool in the fight against the obesity epidemic in the United States. One major determinant of weight gain among adolescents and young adults is the consumption of sugar-sweetened beverages (10-12). Young adults and adolescents consume the most calories from sugar-sweetened sodas of any age group (230 and 200 calories per day, respectively) and add an additional 100 calories per day in juice $(13,14)$.

Successful interventions to reduce sugar-sweetened beverage consumption and decrease risk for weight gain are greatly needed. Prior cafeteria and food service interventions, involving educational messages at the point-of-purchase or price changes, have demonstrated modest success in changing dietary behaviors. Conducted mostly among adults, these interventions, especially pricing interventions, have increased sales of fruits and vegetables in a workplace cafeteria (15) and low-fat snack foods in school and workplace vending machines (16). Others have led to decreased sales of sugar-sweetened sodas in hospital cafeterias $(17,18)$. Given that many college students obtain sugar-sweetened beverages on campus in cafeterias and other retail outlets, a point-of-purchase strategy may have particular promise for reducing consumption in this population.

The goal of this study was to collect the information necessary to design such an intervention in college settings, by exploring how young adults choose beverages and how they respond to intervention messages encouraging them to make healthier choices.

\section{Methods}

We conducted two focus groups in each of six colleges, for a total of 12 focus groups. Focus groups were sex stratified to facilitate free discussion of potentially sensitive issues, including body weight. To account for differences in weight norms, culture, and consumption preferences, we included private colleges in two states from different regions of the United States - Massachusetts in the Northeast and Louisiana in the South. Two colleges in Louisiana were historically-black universities and one in Massachusetts was an all-female college. The colleges had undergraduate enrollments ranging from 1,200 to over 8,000 students.

We recruited participants by posting printed flyers on campus bulletin boards or circulating electronic flyers on campus listservs. We specified that we were looking for students who drank regular soft drinks/sodas. We provided a $\$ 30$ gift card for participating.

We conducted all focus groups at the individual colleges between April and June 2010. Two of the investigators, a physician (JPB) and an anthropologist (REG), jointly facilitated 6 of the 12 focus groups. One investigator facilitated the additional 6 focus groups (JPB -2 , REG - 4). Prior to each focus group, participants completed a brief, anonymous survey that included questions regarding 1) demographics, height, and weight; 2) an open-ended question querying "which beverages do you most commonly drink?"; and 3) a multiplechoice question regarding "which factors determine your choice of beverage?", including possible responses of "taste", "size of beverage", "brand", "number of calories", "price", 
"container type", and "other". During focus groups, we used a guide of open-ended questions to foster a wide-ranging discussion about how students chose non-alcoholic beverages. Core questions were followed up with spontaneous probes, as necessary. We also asked students to respond to several educational advertisements that have been used in studies or public health campaigns to communicate health messages regarding sugarsweetened beverages $(17,19)$.

We audio recorded all focus groups and transcribed them verbatim. Three of the investigators (JPB, SKL, REG) read the transcripts and repeatedly met to conduct content analysis, incorporating the principles of the immersion-crystallization method (20). This qualitative approach consists of individually reviewing the focus group recordings and transcriptions, then discussing the data as a group to determine emerging themes. After identifying salient themes and topical categories within the data, our team developed, tested, and refined a data codebook. We used WeftQDA qualitative data coding software to do lineby-line coding and to manage and sort the large quantity of data (21). For this study, coding did not constitute the entirety of the analysis as it might in other qualitative studies. Rather, coding was a data management tool that facilitated the analysis process we conducted as a team. Having the data coded after the team read each transcript in its entirety facilitated efficient identification of particular topics of interest for further discussion and analysis. Through this process we also were able to identify any coding discrepancies. As a group we discussed and resolved these discrepancies to ensure quality and consistency; in all cases of coding discrepancies, the team was able to collectively determine a final code. Following coding, we resumed our group meetings to complete data analysis and interpretation of themes until no new themes emerged.

The Institutional Review Boards of Harvard Pilgrim Health Care, Inc. and each of the six colleges that were sites for focus groups approved this study.

\section{Results}

The mean number of participants per focus group was 7.5 (range 2 to 11), with 90 total participants. Mean age was 19 years, and $63 \%$ were female (Table 1). Half self-identified as white and $47 \%$ as black. The most commonly consumed beverages were water $(72 \%)$, juice (72\%), and sugar-sweetened soda (68\%) (Table 2). Nearly all (93\%) participants reported that taste was an important factor in determining beverage choice followed by price (58\%) and calorie content (30\%).

In the focus group discussions, several important themes emerged as factors in beverage choice: taste is paramount; price is important but secondary; health and nutritional content of beverages are of limited interest; juice has a "health halo"; and water is consumed primarily for hydration. The themes reported in focus groups in Louisiana and Massachusetts and among men and women were similar; therefore, we report combined results across all focus groups.

\section{Taste is paramount}

Taste was the most important reason for choosing a beverage. Many of the students echoed one male's sentiment, "If it tastes good, I'm drinking it." Many were obsessed with favorite sugar-sweetened beverage brands, describing with obvious pleasure what they enjoyed about particular beverages and how they had no intention of cutting down their consumption: "I want to drink my favorite drinks until the day that [I'm] going to die, and then when I'm on my deathbed, I'll have one of my favorite drinks with me." Because of their strong affinity to specific beverages, they believed changing to another option would be difficult: "It takes ... something like really drastic to change." Some acknowledged that their fixation on 
certain beverages was akin to addiction and that taste often overpowered a rational calculation of the potential harm in drinking sugar-sweetened beverages: "I' $m$ trying to stop drinking soda, but I can't resist Sprite ${ }^{\circledR}$."

A minority of students drank diet beverages, and those that did regularly claimed to do so because they preferred the taste rather than due to a concern about sugar or calories. Most students, however, strongly disliked the taste of diet beverages. As one male student stated, "The only way I can deal with it, if you drink it all fast. It leaves an aftertaste in your mouth."

\section{Price is important but secondary}

Price was the next most commonly mentioned factor influencing students' beverage choices, especially for the majority of students who reported having limited funds. As one female student asserted, the "only label I look at is the price label." If choosing between two similar items, they would opt for the lower priced item but only if the choice did not sacrifice taste.

Many students across all focus groups expressed devotion to AriZona ${ }^{\circledR}$ Iced Tea. What drove their enthusiasm was their sense of almost wonderment that such a good tasting item came in a large can, priced less than a dollar. As one male reported, "I'm constantly drinking those AriZonas. They're a buck." Spending one dollar or less, especially for a large beverage, was repeatedly acknowledged as a motivating factor in choosing a beverage, not just AriZona Iced Tea. Even a marginal cost above one dollar was sometimes a deterrent against choosing a beverage, especially if there was an alternative for less. Students did not believe they could be swayed to a different beverage choice if it was a matter of cents. As a male student aptly explained, after "breaking a dollar, I don't care what the cents are."

Having access to free beverages was important to some and was at times a motivation to drink water. Few had tolerance for purchasing water: "I don't really try and buy water because you can get water for free." A barrier to free water was concern about the taste and appearance of tap water, and filtered water was preferred.

Taste typically dominated price. Participants noted that they frequently overspent to drink the beverages they craved: "I don't care about the price. I will get it." Students using swipe cards for purchases on campus were most likely to report insensitivity to price until their card was depleted. Most reported that if given the choice between water and a beverage with flavor, with other factors such as price held constant, they would always choose the beverage with flavor: "I want some water, but the water is the same price as the soda. Might as well go ahead and get some flavor."

\section{Health and nutritional content of beverages are of limited interest}

Health and calorie content had limited influence on beverage choices for most of the participants, male and female. Students commonly cited their youth as a factor in their disregard for potential health dangers of sugar-sweetened beverage consumption: "I'm young now. I'm not really paying attention to [health and diet]." And, "I just have a lot of other priorities besides what I eat and drink." Several students mentioned that they did not know their daily calorie requirement and could not make any assessment about the calories of a particular beverage: "Honestly, I don't even know what the numbers mean. Six hundred? Now, is that good or bad?"

If students were mindful of calorie consumption at all, they more commonly viewed food but not beverages as the critical consideration: "Calories [are] actually the last thing on my mind when ... drinking something. Likely when I'm eating something, that's different." "A drink you might be less likely to think about it because you can't look at this and be like - 
oh I see like the fat in it." Students also reported that school nutritional lessons addressed food and water but not sugar-sweetened beverages. As a female student explained, "Health forums ... mostly focus on food" and "how much water you should drink, but they never say well how much juice you shouldn't drink."

For the minority of students who did report calorie and nutritional content as important considerations when choosing beverages, they mostly drank water and identified reasons such as: trying to lose weight ("I switched off sodas for health reasons ... trying to lose weight"); counterbalancing other intake ("I'll make a conscious effort to stick to water because I know I'll be drinking beer [later]" or "I would rather have a cookie or something and water than a soda"); or avoiding high intake of sugar ("I just get more worried about all the sugar", and "I think I've been lectured on that more ... than calories"). Many were quick to dismiss the negative consequences of sugar and calorie overconsumption because they felt they were frequently walking around campus or exercising and could easily "work it off" or "burn it all off." Due to the widespread distaste for diet sodas among the participants, few noted the calorie reduction that they could attain by switching to diet sodas.

Diabetes commonly arose as a reason for monitoring dietary intake generally, not specific to beverages. Some students had a family history of diabetes and acknowledged that they must reduce their risk at some point. However, they were confident that any health-related dietary changes could be safely put off until the future. As both male and female students explained, "you're still invincible" and "you don't think about it until you get older, and it really becomes a health issue because you're old, and your body is a little, I guess, weaker." Another female noted, "I just like to live life and not be paranoid."

Among the most reported health concerns regarding soda were bewilderment about the seemingly mysterious chemical content of sodas. For example, students mentioned the following soda "facts": Coke ${ }^{\circledR}$ can "erode dirt from coins"; "One of the solvents we used [in chemistry lab] and that's in Coke;" "You have a clogged drain, you throw the Coke bottle in the clogged drain, it will unclog it. So it's like that's what it's doing to your internal organs." However, students often followed these statements by expressing a persistent desire to consume sodas because of the taste: "People still drink Coke, and they use Coke to take acid off a car battery!"

Diet beverages also were criticized for their chemical content, and some thought diet sodas were more dangerous than regular sodas: "Aspartame gives you cancer. Remember that when you drink diet soda." Another female student was skeptical that sodas labeled "diet" were even low calorie: "I think they have equal as many calories ... I think [Diet Pepsi ${ }^{\circledR}$ ] is equal to regular Pepsi ${ }^{\circledR}$."

\section{Juice has a "health halo"}

Students drank juice frequently and often identified the taste as a principal reason. However, the health benefits of juice were often mentioned as a contrast to soda: "If it's orange juice, you think about all the good vitamins you're getting, and it doesn't seem as bad - I'm pretty sure soda doesn't have vitamin C in it. So I don't really worry about the sugar in juice as much." Similarly, when students recognized that both soda and juice had substantial amounts of sugar, they still believed that juice was healthier: "They're connected [juice and soda] on the fact that there is a lot of sugar in both", but "as far as calories go, they're good calories with juice most of the time," as compared to soda. 100\% juices were noted as particularly healthy options; juices "from concentrate" were viewed less favorably. These sentiments were not universal, as a small number of students stated that "Juice is as unhealthy as soda." 


\section{Water is consumed primarily for hydration}

While some students drank water at times because it was "free" or "cheap," "helps with overall energy," or was "healthier" and promoted weight loss, most of the students identified hydration as the primary reason for consuming water. One male student stated, "It's also good for you to be hydrated; like it helps with your overall health in every aspect." Some students identified dehydration as a common aspect of being a student, with water as the remedy: "I don't really like water because there's not any taste. I just drink it because I have to," and "You drink water for the hydration piece of it but other things you drink for the taste." Heavy alcohol consumption was a reason cited by men and women for being dehydrated and requiring water: "We drink water all day" in preparation for a night of drinking; "After that long night you need water when you first wake up," and water "definitely helps when I'm hung over."

\section{Racial differences among focus groups participants}

Although black and white students were mostly similar in their perspectives and behaviors regarding beverages, health was less of a consideration to the black students. In the prefocus group survey, $60 \%$ of white versus $0 \%$ of black students reported calorie content as a factor in their choice of beverages.

In the focus groups, white students also more commonly raised health and calorie content of beverages as a consideration in their choices. An exception to this was that more black students mentioned diabetes as a health concern when choosing what to eat or drink. They did so in large part because of personal experience with diabetic family members. As one black woman stated, diabetes "is high in black people, so I try and keep that statistic down" by "running track", and "I rarely eat candy now."

\section{Influence of potential health messaging campaigns in colleges}

Students regarded powerful and shocking health messaging that captured their attention as a possible influence on beverage choices. Students claimed that graphical representations of the health consequences of beverage consumption were most powerful, especially with "something that scares you" or that presents "visceral" content. When presented with a New York City Board of Health flyer that illustrates soda transforming into fat when poured from a bottle into a glass, nearly all reported this advertisement to be quite effective. They described it as "gross" and, as a result, said it would "catch my eye" and "make me never want to drink another pop again." Additional New York City Board of Health advertisements graphically showing the amount of sugar in beverages were received favorably because of their shock appeal: "Just the thought of putting 16 teaspoons ... into a drink is repulsive to me."

\section{Discussion}

Through focus groups conducted in six colleges, we found that beverage preferences are strongly ingrained and determined primarily by taste. Price also was important for students with a strong affinity for beverages that were less than one dollar. Health factors were a distant third consideration for most students with some stating a concern for diabetes, high sugar intake, and the consumption of chemicals. Calorie intake was deemed relatively unimportant, especially for black students, because of a lack of awareness of calories in general and a tendency to ignore calorie content of beverages in contrast to calorie content of food.

Consistent themes across the diverse college settings, including co-educational institutions, an all-female college, and two historically-black colleges, strengthen our results. We found 
few substantive differences related to the race and gender of participants except for less interest in beverage calorie content among black students and more awareness and discussion regarding risk factors for diabetes, also among black students.

In this qualitative, focus group study, we found that a diverse group of college students have preferences for strong educational messaging. These results could have implications for intervention planning. First, students found graphical educational messages, especially shocking images, more compelling than textual messages. Such messages may be particularly useful for convincing students to reduce consumption of juice, which had a "health halo". Second, black students may respond to messages regarding diabetes risk reduction because of their heightened personal experiences with diabetes. Third, messaging could leverage students' concerns about intake of what they perceive to be soda's unnatural and mysterious ingredients. Fourth, despite lack of attention to calorie content of beverages, students did pay some attention to calories in food. An intervention might present beverage calorie content in food currency, such as displaying the calorie equivalence between a 20 ounce sugar-sweetened soda and one-half of a Big Mac ${ }^{\circledR}$.

Pricing interventions also may be helpful in encouraging students to switch from sugarsweetened beverages to water. An intervention that provided filtered water free of charge in cafeterias and throughout campus might be most effective because of student preferences for free items, a concept that has been extensively explored in behavioral economics (22). If selling water is required, pricing it at less than one dollar may be enough to motivate students to choose water.

In conclusion, we found that students have strong preferences for beverages, based on taste primarily but also price. Health considerations were secondary. Several themes emerged that might facilitate success of interventions designed to decrease college students' consumption of sugar-sweetened beverages, such as the use of powerful graphical images or pricing interventions.

\section{Acknowledgments}

This work was conducted with support from Harvard Catalyst | The Harvard Clinical and Translational Science Center (National Center for Research Resources and the National Center for Advancing Translational Sciences, National Institutes of Health Award \#UL1 RR 025758 and financial contributions from Harvard University and its affiliated academic health care centers). This work was also supported by a P30 center grant from the National Heart, Lung, and Blood Institute (P30 HL101312-01, PI: Gillman)

These study sponsors had no role in the study design, collection of data, data analysis and interpretation of results, the writing of the manuscript, or the decision to submit the manuscript for publication. Dr. Block wrote the first draft of this manuscript; all individuals contributing to this work are authors of this manuscript. Dr. Block, Ms. Linakis, and Dr. Goldman received salary support for this study from the funding sources listed above. The content is solely the responsibility of the authors and does not necessarily represent the official views of Harvard Catalyst, Harvard University and its affiliated academic health care centers, or the National Institutes of Health.

\section{References}

1. Field AE, Cook NR, Gillman MW. Weight status in childhood as a predictor of becoming overweight or hypertensive in early adulthood. Obes Res. 2005; 13:163-9. [PubMed: 15761176]

2. Whitaker RC, Wright JA, Pepe MS, Seidel KD, Dietz WH. Predicting obesity in young adulthood from childhood and parental obesity. N Engl J Med. 1997; 337:869-73. [PubMed: 9302300]

3. Ogden CL, Carroll MD, Kit BK, Flegal KM. Prevalence of obesity and trends in body mass index among US children and adolescents. JAMA. 1999-2010; 307:483-90. [PubMed: 22253364]

4. Sabo RT, Lu Z, Daniels S, Sun SS. Serial Childhood BMI and Associations With Adult Hypertension and Obesity: The Fels Longitudinal Study. Obesity (Silver Spring). 
5. Holm-Denoma JM, Joiner TE, Vohs KD, Heatherton TF. The "freshman fifteen" (the "freshman five" actually): predictors and possible explanations. Health Psychol. 2008; 27:S3-9. [PubMed: 18248103]

6. Lloyd-Richardson EE, Bailey S, Fava JL, Wing R. A prospective study of weight gain during the college freshman and sophomore years. Prev Med. 2009; 48:256-61. [PubMed: 19146870]

7. Nelson MC, Story M, Larson NI, Neumark-Sztainer D, Lytle LA. Emerging adulthood and collegeaged youth: an overlooked age for weight-related behavior change. Obesity (Silver Spring). 2008; 16:2205-11. [PubMed: 18719665]

8. Racette SB, Deusinger SS, Strube MJ, Highstein GR, Deusinger RH. Weight changes, exercise, and dietary patterns during freshman and sophomore years of college. J Am Coll Health. 2005; 53:24551. [PubMed: 15900988]

9. Vella-Zarb RA, Elgar FJ. The 'freshman 5': a meta-analysis of weight gain in the freshman year of college. J Am Coll Health. 2009; 58:161-6. [PubMed: 19892653]

10. Schulze MB, Manson JE, Ludwig DS, et al. Sugar-sweetened beverages, weight gain, and incidence of type 2 diabetes in young and middle-aged women. JAMA. 2004; 292:927-34. [PubMed: 15328324]

11. Dhingra R, Sullivan L, Jacques PF, et al. Soft drink consumption and risk of developing cardiometabolic risk factors and the metabolic syndrome in middle-aged adults in the community. Circulation. 2007; 116:480-8. [PubMed: 17646581]

12. Ludwig DS, Peterson KE, Gortmaker SL. Relation between consumption of sugar-sweetened drinks and childhood obesity: a prospective, observational analysis. Lancet. 2001; 357:505-8. [PubMed: 11229668]

13. Nielsen SJ, Popkin BM. Changes in beverage intake between 1977 and 2001. Am J Prev Med. 2004; 27:205-10. [PubMed: 15450632]

14. Wang YC, Bleich SN, Gortmaker SL. Increasing caloric contribution from sugar-sweetened beverages and 100\% fruit juices among US children and adolescents, 1988-2004. Pediatrics. 2008; 121:e1604-14. [PubMed: 18519465]

15. Jeffery RW, French SA, Raether C, Baxter JE. An environmental intervention to increase fruit and salad purchases in a cafeteria. Prev Med. 1994; 23:788-92. [PubMed: 7855111]

16. French SA, Jeffery RW, Story M, et al. Pricing and promotion effects on low-fat vending snack purchases: the CHIPS Study. Am J Public Health. 2001; 91:112-7. [PubMed: 11189801]

17. Block JP, Chandra A, McManus KD, Willett WC. Point-of-purchase price and education intervention to reduce consumption of sugary soft drinks. Am J Public Health. 2010; 100:1427-33. [PubMed: 20558801]

18. Thorndike AN, Sonnenberg L, Riis J, Barraclough S, Levy DE. A 2-phase labeling and choice architecture intervention to improve healthy food and beverage choices. Am J Public Health. 2012; 102:527-33. [PubMed: 22390518]

19. New York City Department of Health and Mental Hygeine. Health Bulletin. 2006

20. Borkan, J. Crystallization-Immersion. In: Crabtree, B.; Miller, W., editors. Doing Qualitative Research. Sage Publications; Thousand Oaks, CA: 1999. p. 179-94.

21. Weft QDA: A free qualitative analysis software application

22. Ariely, D. Predictably irrational: the hidden forces that shape our decisions. HarperCollins; New York: 2008.

23. Yamamoto JA, Yamamoto JB, Yamamoto BE, Yamamoto LG. Adolescent fast food and restaurant ordering behavior with and without calorie and fat content menu information. J Adolesc Health. 2005; 37:397-402. [PubMed: 16227125]

24. Elbel B, Gyamfi J, Kersh R. Child and adolescent fast-food choice and the influence of calorie labeling: a natural experiment. Int J Obes (Lond). 2011; 35:493-500. [PubMed: 21326209]

25. Aaron J, Evans R, Mela D. Paradoxical effects of a nutrition labeling scheme in a student cafeteria. Nutrition Research. 1995; 15:1251-61. 


\section{Implications and Contribution}

Among students at six colleges, taste and price, not health, were the dominant factors for choosing beverages. To reduce the high sugar-sweetened beverage intake in this population, students felt that interventions using shocking visual images or providing low-cost or free water would be required to overcome preferences. 
Table 1

Characteristics of 90 Focus Group Participants at 6 Colleges

\begin{tabular}{|c|c|c|}
\hline \multicolumn{2}{|l|}{ Characteristic } & Mean $(\mathrm{SD}$, range) or $\mathrm{N}(\%)$ \\
\hline \multicolumn{2}{|l|}{ Age, mean, y } & $19(0.9,17-22)$ \\
\hline \multicolumn{2}{|l|}{ BMI, mean, $\mathrm{kg} / \mathrm{m}^{2}$} & $24.5(4.6,17.5-40.2)$ \\
\hline \multicolumn{2}{|l|}{ Female sex } & $57(63 \%)$ \\
\hline \multirow[t]{5}{*}{ Race/Ethnicity ${ }^{a}$} & White & $45(50 \%)$ \\
\hline & Black & $42(47 \%)$ \\
\hline & Hispanic & $4(4 \%)$ \\
\hline & Asian & $4(4 \%)$ \\
\hline & Other & $1(1 \%)$ \\
\hline \multirow[t]{3}{*}{ Year in School } & Freshman & $48(54 \%)$ \\
\hline & Sophomore & $39(44 \%)$ \\
\hline & Junior & $2(2 \%)$ \\
\hline
\end{tabular}

${ }^{a}$ Participants could enter more than one response. 
Table 2

Beverages Consumed by Participants and Factors in Beverage Choices

\begin{tabular}{|c|c|}
\hline & $\mathbf{N}(\%)$ \\
\hline \multicolumn{2}{|c|}{ Most Commonly Consumed Beverages } \\
\hline Juice & $65(72 \%)$ \\
\hline Water & $65(72 \%)$ \\
\hline Sugar-sweetened Soda $b$ & $61(68 \%)$ \\
\hline Tea & $32(36 \%)$ \\
\hline Diet Soda $b$ & $16(18 \%)$ \\
\hline Milk & $13(14 \%)$ \\
\hline Coffee & $11(12 \%)$ \\
\hline Energy Drinks & $4(4 \%)$ \\
\hline \multicolumn{2}{|c|}{ Factors in Beverage Choices ${ }^{c}$} \\
\hline Taste & $84(93 \%)$ \\
\hline Price & $52(58 \%)$ \\
\hline Calories & $27(30 \%)$ \\
\hline Brand & $22(24 \%)$ \\
\hline Size & $21(23 \%)$ \\
\hline Other $^{d}$ & $14(16 \%)$ \\
\hline Container type & $13(14 \%)$ \\
\hline
\end{tabular}

a We asked students to list up to 5 of their most commonly consumed beverages

$b_{10 \%}$ of subjects reported consuming diet soda and no sugar-sweetened soda. $4 \%$ reported only "soda" consumption without specifying diet versus regular. These respondents were not included in either diet or sugar-sweetened soda categories.

${ }^{c}$ Participants could enter more than one response.

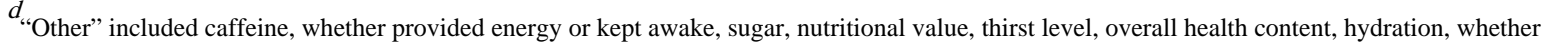
real juice, and availability in the school cafeteria. 